\title{
Broadening the variability of quality traits in rapeseed through interspecific hybridization with an application of immature embryo culture
}

\author{
JANETta NiEmanN*, ANDRZEJ WoJCIEChOWSKi, Jowita JANOWICZ \\ Department of Genetics and Plant Breeding, Poznań University of Life Sciences, Poznań, Poland \\ *Corresponding author: niemann@up.poznan.pl
}

\begin{abstract}
Interspecific hybridization is an important tool to transfer characters across species and develop synthetic amphidiploids, and therefore it has been widely applied for improving Brassica spp. The aim of our study was to determine whether the interspecific crosses can help increase the range of variability of traits connected with the higher value of rapeseed. An attempt was also made to investigate the environmental influence on the studied traits. For this reason, in our experiments, crosses between male sterile line of F8 generation and $B$. campestris ssp. sarson, Yellow sarson; B. campestris ssp. pekinensis; B. carinata and B. juncea were first attempted. Thereafter, hybrid seeds of 96 lines obtained by crossing Brassica napus male sterile line MS8 with three other Brassica species were tested for fiber and glucosinolates content using near-infrared reflectance spectroscopy (NIRS). Moreover, chromatography and spectrophotometric measurements of sinapine and tocopherols contents in those seeds were made. On the basis of the obtained results, it was found that all tested hybrid lines showed a great increase of variability for the studied quality traits when compared to the parental forms. As a result of our analyses, reduced glucosinolates hybrid lines were selected.
\end{abstract}

Key words: interspecific hybridization, quality traits, infrared reflectance spectroscopy (NIRS), glucosinolates, sinapine, fiber

\section{Introduction}

The improvement of Brassica species has been mostly confined to the exploitation of the naturally occurring genetic variation in the cultivated species. The existing variation being limited, breeders have to resort to wide hybridization, which provides an important method of incorporation of desirable characteristics such as, resistance to disease, drought and frost. Moreover, artificial hybridization among the Brassica species may be useful for providing further approaches and novel traits in oilseed Brassica research and breeding programs. It is interesting especially because of the growing interest in rapeseed oil, which is connected with large possibilities of its use both for industrial and consumption purposes. In highly developed American countries as well as the European Union countries and China, there is an increasing emphasis on the oil quality (Olejniczak et al., 2007). The oil content in the seed varies from $30-45 \%$ depending on the species, the variety and the climatic conditions under which it is grown. Following oil extraction, the remaining meal contains different nutritional and anti-nutritional compounds. The quality of rapeseed oil and meal depends, in particular, on the content of anti-nutritional compounds in the seeds (e.g. glucosinolates, sinapine and fiber). Among these, glucosinolates are the most important anti-nutritional compounds. The optimal content of glucosinolates in seeds, considered harmless at current cultivated varieties of oilseed rape, is in the range of $10-20 \mu \mathrm{M} / \mathrm{g}$. For many years an increased interest has been observed among Brassica researchers in the lowering of the sinapine content, which lowers the nutritional value of rapeseed meal (Wojciechowski et al., 1994; Velasco et al., 1998; zum Felde, 2005). Within the Brassica genera there is a large variation in sinapine content, which consequently creates the possibility of selecting lines with reduced sinapine synthesis (zum Felde, 2005). Furthermore, in rapeseed seeds, another important anti-nutri- 
tional component is high fiber content. Compared with black or brown seeds, yellow-seeded rapeseed cultivars have a thinner seed coat, which is associated with the higher oil content in the seeds and a higher protein and lower fiber content in the meals (Chen and Heneen, 1992). For this reason, crosses between Brassica napus, and yellow seeded Brassica campestris ssp. trilocularis "Yellow sarson" were made. One of the most effective methods for increasing the variability of traits that impacts the quality of rapeseed products is interspecific hybridization. However, information on the genetic variation created through such crosses is meager. Therefore, the major objectives of the present study were to create a genetic variation through interspecific crosses of $B$. napus with chosen Brassica species and estimate variability parameters for different seed quality traits in the obtained hybrid lines.

\section{Materials and methods}

The interspecific hybridization was performed in the glasshouse of the Genetics and Plant Breeding Department, Poznań University of Life Sciences (PULS) in Poznan, Poland. There were 4 different cross combinations and one control (Table 1). Depending on the availability of flower buds, 30-60 crosses were made for each cross combination. All hybridizations were performed with the application of an in vitro culture of isolated embryos according to the method described by Wojciechowski $(1985,1998)$. The immature embryos were isolated from young siliques at different developmental stages i.e. heart and early and late torpedo stages, 14-19 days after pollination. For the embryo culture, basal White (W, 1963), Murashige and Skoog (MS, 1962), Murashige and Skoog modified by Keller and Armstrong $\left(\mathrm{MS}_{\mathrm{k}}, 1977\right)$ and Nitsh and Nitsh $\left(\mathrm{H}_{3}, 1969\right)$ media were applied (Fig. 1). During the season $2010 / 2011$, ninety six $F_{5}$ hybrid lines were grown in two different locations i.e. the experimental fields in Poznań (Sołacz) and in the PULS experimental station Dłoń located $100 \mathrm{~km}$ south of Poznań. These two locations have different types of soil and weather conditions. In Poznań, the soil is light and sandy type (class IV in the soil valuation system), whereas in Dłoń, the soil is heavy (class III). During the growing season, the average temperature in Poznań was lower than in Dłoń, i.e. $11.9^{\circ} \mathrm{C}$ and $15^{\circ} \mathrm{C}$, respectively. Similarly, the average rainfall was lower in Poznań (about $59.8 \mathrm{~mm}$ ) than in Dłoń
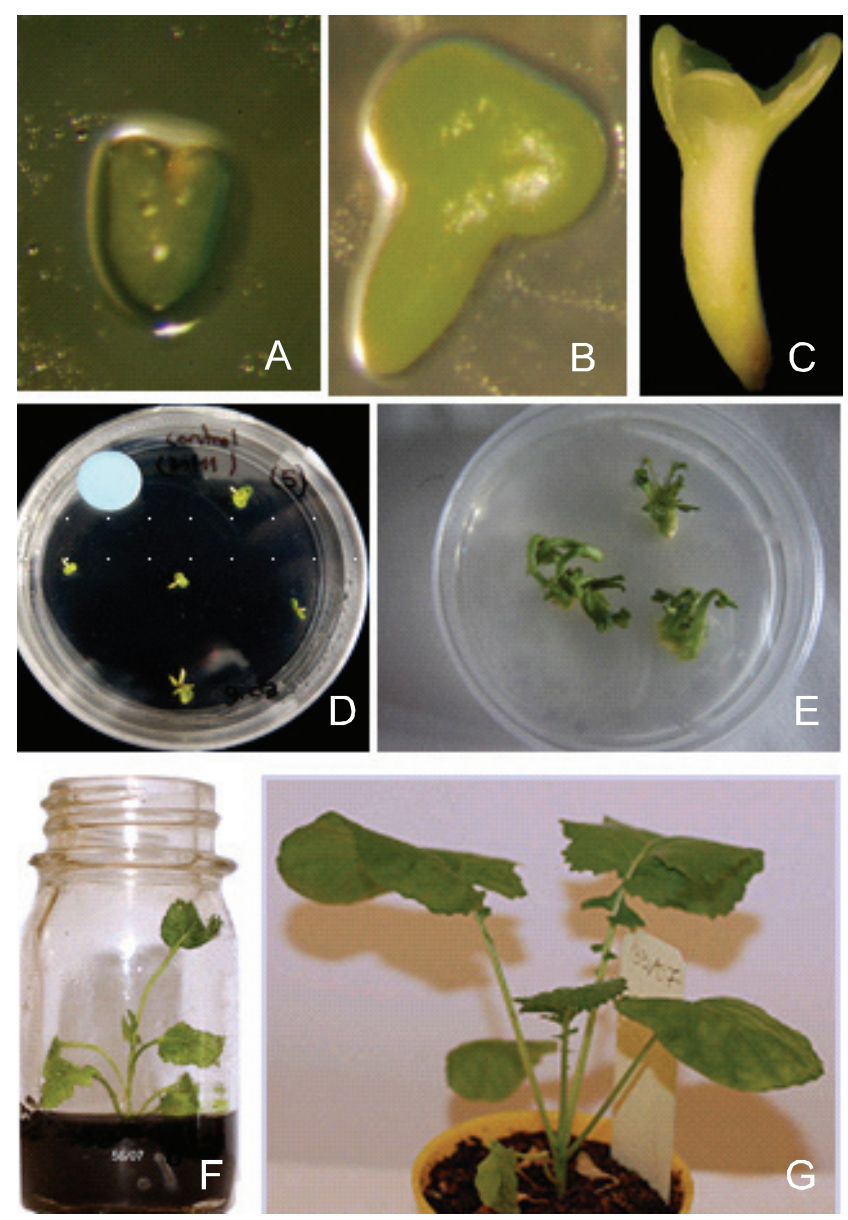

Fig. 1. Plant regeneration from Brassica hybrid embryos in in vitro cultures: A-C) Hart, torpedo and late torpedo stage of Brassica hybrid embryos just after isolation from the silique; D) First day of incubation of hybrid embryos on MS medium; E) Regenerated seedlings on $\mathrm{MS}_{\mathrm{k}}$ medium; F) Regenerated plant on rooting $\mathrm{H}_{3}$ medium; $\mathrm{G}$ ) Regenerated plant in the soil

$(70.5 \mathrm{~mm})$. The seed samples for the analysis of glucosinolates, fiber and sinapine concentration were collected from ten self-pollinated plants from each tested line. Glucosinolates and fiber content was determined by nearinfrared reflectance spectroscopy (NIRS) (Thies, 1982, Biston et al., 1988, Velasco et al., 1999). These analyses were performed at the Małyszyn Laboratory that belongs to Plant Breeding Strzelce. For the NIRS analyses, minimum $3 \mathrm{~g}$ of intact seeds were used. Such a seed probe was scanned on the NIRS Systems monochromator model 6500 (NIR Systems, Inc. Silver Springers, MD, USA). The sinapine content (total sinapic acid esters) was determined by spectrophotometric method. The sinapine content was calculated in accordance with the formula described by Wojciechowski et al. (1994). The compound was analyzed in the PULS laboratory in Poznań. 
Table 1. The effectiveness of interspecific crosses between male sterile line of Brassica napus MS- 8 (AACC $=38$ ) and four Brassica species expressed by number of obtained embryos to mean number of well-developed ovules

\begin{tabular}{|c|c|c|c|c|c|c|c|}
\hline \multicolumn{2}{|r|}{ Cross combination } & \multicolumn{3}{|c|}{ Number } & \multirow{2}{*}{$\begin{array}{c}\text { Ovules } \\
\text { with embryos } \\
{[\%]}\end{array}$} & \multicolumn{2}{|c|}{$\begin{array}{l}\text { Regenerated plants } \\
\text { (\% plants/incubated } \\
\text { embryos) }\end{array}$} \\
\hline 우 & $\sigma^{x}$ & $\begin{array}{l}\text { analyzed } \\
\text { pods }\end{array}$ & $\begin{array}{l}\text { isolated } \\
\text { ovules }\end{array}$ & $\begin{array}{l}\text { embryos } \\
\text { placed } \\
\text { on media }\end{array}$ & & $\begin{array}{l}\text { on } \mathrm{H} 3 \\
\text { medium }\end{array}$ & in soil \\
\hline \multirow{5}{*}{$\begin{array}{l}\text { B. napus } \\
\text { - MS8 line }\end{array}$} & $\begin{array}{l}\text { B. campestris ssp. trilocularis } \\
\text { "Yellow Sarson" - turnip rape }\end{array}$ & 21 & 319 & 162 & 50.7 & 56.4 & 48.1 \\
\hline & $\begin{array}{l}\text { B. campestris ssp. pekinensis } \\
\text { - pekinense cabbage }\end{array}$ & 34 & 158 & 97 & 61.3 & 62.1 & 43.1 \\
\hline & B. carinata - Ethipian mustard & 49 & 874 & 179 & 20.5 & 51.17 & 41.3 \\
\hline & B. juncea - Indian mustard & 10 & 113 & 31 & 27.4 & 41.5 & 41.5 \\
\hline & B. napus - Lira Jet & 6 & 83 & 82 & 98.8 & 100.0 & 100.0 \\
\hline \multicolumn{2}{|l|}{ Total } & 120 & 1547 & 551 & 35.6 & 50.0 & 43.7 \\
\hline
\end{tabular}

Table 2. Glucosinolate content $[\mu \mathrm{mol} / \mathrm{g}]$ s.d.m in the seeds of interspecific hybrids obtained by crossing Brassica napus male sterile line MS-8 (AACC = 38) with yellow seeded B. campestris ssp. trilocularis "Yellow Sarson" - (A1A1 = 20), brown - seeded B. campestris ssp. pekinensis $(\mathrm{A} 2 \mathrm{~A} 2=20), B$. carinata $(\mathrm{BBCC}=34)$ and with $B$. juncea $-(\mathrm{AABB}=18)$ depending on the location - Dłoń (D), Poznań-Sołacz (S)

\begin{tabular}{|c|c|c|c|c|c|c|c|c|c|c|c|c|}
\hline \multirow{2}{*}{\multicolumn{2}{|c|}{$\begin{array}{l}\text { Hybrids and } \\
\text { parental forms }\end{array}$}} & \multirow{3}{*}{\begin{tabular}{|c|} 
Location \\
$\mathrm{S}$
\end{tabular}} & \multicolumn{5}{|c|}{ Alkene } & \multicolumn{5}{|c|}{ Total glucosinolate content } \\
\hline & & & \multirow{2}{*}{$\begin{array}{l}\text { mean } \\
18.60\end{array}$} & \multirow{2}{*}{$\begin{array}{c}\text { range } \\
-\end{array}$} & \multirow{2}{*}{$\begin{array}{c}\mathrm{SLD}_{0,05} \\
-\end{array}$} & \multirow{2}{*}{$\begin{array}{c}\text { SD } \\
-\end{array}$} & \multirow{2}{*}{$\begin{array}{c}\text { Var } \\
-\end{array}$} & \multirow{2}{*}{$\begin{array}{l}\text { mean } \\
20.78\end{array}$} & \multirow[t]{2}{*}{ range } & \multirow{2}{*}{$\begin{array}{c}\mathrm{SLD}_{0,05} \\
-\end{array}$} & \multirow{2}{*}{$\begin{array}{c}\mathrm{SD} \\
-\end{array}$} & \multirow{2}{*}{$\begin{array}{c}\text { Var } \\
-\end{array}$} \\
\hline 우 & $\mathrm{AC}$ & & & & & & & & & & & \\
\hline \multirow{2}{*}{\multicolumn{2}{|c|}{$\begin{array}{l}\mathrm{AC} \times \mathrm{A} 1 \\
(16 \text { lines })\end{array}$}} & $\mathrm{D}$ & 44.57 & 10.94-78.05 & 4.29 & 20.41 & 416.72 & 46.22 & $16.04-76.96$ & 3.95 & 18.81 & 353.84 \\
\hline & & $\mathrm{S}$ & 36.03 & $6.43-69.40$ & 5.82 & 20.56 & 422.85 & 37.73 & $10.94-69.10$ & 5.18 & 18.31 & 335.27 \\
\hline$\sigma^{\pi}$ & A1 & $\mathrm{S}$ & 57.18 & - & - & - & - & 56.87 & - & & & - \\
\hline \multirow{2}{*}{\multicolumn{2}{|c|}{$\begin{array}{l}\mathrm{AC} \times \mathrm{A} 2 \\
(56 \text { lines })\end{array}$}} & $\mathrm{D}$ & 40.91 & $4.96-101.08$ & 2.34 & 22.45 & 947.70 & 42.53 & $6.81-98.16$ & 2.17 & 20.79 & 831.52 \\
\hline & & $\mathrm{S}$ & 40.40 & $10.48-64.99$ & 3.86 & 13.21 & 174.57 & 41.34 & $14.08-62.45$ & 3.48 & 11.91 & 141.83 \\
\hline$\sigma^{x}$ & $\mathrm{~A} 2$ & $\mathrm{~S}$ & 46.14 & - & - & - & - & 7.28 & - & - & - & - \\
\hline \multirow{2}{*}{\multicolumn{2}{|c|}{$\begin{array}{l}\mathrm{AC} \times \mathrm{BC} \\
(10 \text { lines })\end{array}$}} & $\mathrm{D}$ & 43.03 & $10.82-79.56$ & 5.00 & 17.12 & 293.03 & 44.18 & $16.03-77.52$ & 4.55 & 15.56 & 242.15 \\
\hline & & $\mathrm{S}$ & 43.69 & $35.84-53.47$ & 2.47 & 5.35 & 28.66 & 44.02 & $37.81-53.74$ & 2.29 & 4.95 & 24.48 \\
\hline$\sigma^{x}$ & $\mathrm{BC}$ & $\mathrm{S}$ & 51.22 & - & - & - & - & 52.22 & - & - & - & - \\
\hline \multirow{2}{*}{\multicolumn{2}{|c|}{$\begin{array}{l}\mathrm{AC} \times \mathrm{AB} \\
(14 \text { lines })\end{array}$}} & $\mathrm{D}$ & 39.80 & 11.11-67.95 & 6.29 & 20.80 & 432.53 & 41.52 & $15.47-66.24$ & 5.66 & 18.70 & 34.76 \\
\hline & & $\mathrm{S}$ & 40.16 & $9.70-63.54$ & 5.74 & 19.46 & 417.35 & 39.82 & $12.34-61.29$ & 5.19 & 18.23 & 331.12 \\
\hline$\sigma^{x}$ & $\mathrm{AB}$ & $\mathrm{S}$ & 53.13 & - & - & - & - & 56.28 & - & - & - & - \\
\hline $\begin{array}{l}\text { Control } \\
\text { - Lira Jet }\end{array}$ & & S & 9.83 & - & - & - & - & 12.84 & - & - & - & - \\
\hline
\end{tabular}

The results of chemical analyses were verified by analysis of variance (ANOVA) in accordance with the established experimental method. ANOVA and the analysis of significant differences among the means was perfor- med with the use of STATISTICA computer package. The least significant difference (LSD) at $P=0.05$ level was calculated. 


\section{Results}

\section{The effectiveness of the crosses}

The hybridization efficiency was expressed by the number of obtained embryos to the mean number of well-developed ovules (Table 1). The highest efficiency was observed for B. napus MS8 line x B. campestris ssp. trilocularis "Yellow sarson". In this cross combination, plants were obtained from $48.1 \%$ of isolated embryos. In other combinations, plants were regenerated from 41.3 to $43.7 \%$ of isolated embryos.

\section{The seed analysis}

Hybrid seeds from 96 lines were harvested and examined for anti-nutrient content.

\section{Glucosinolates (GLS) content}

The alkene GLS content in the analyzed parental forms ranged from $18.60 \mu \mathrm{mol} / \mathrm{g}$ seeds (MS8 line) to $53.13 \mu \mathrm{mol} / \mathrm{g}$ ( $B$. juncea), and the total GLS content spanned from 20.78 to 56.28 , respectively as in the case of alkene GLS content (Table 2). The hybrid seeds of four cross combinations exhibited intermediate values for GLS content between the parental forms, and in the case of alkene, the GLS content ranged from 36.03 (MS8 x B. campestris ssp. trilocularis, harvested in Poznań) to $44.57 \mu \mathrm{mol} / \mathrm{g}$ seeds harvested in Dłoń. Similar to alkene GLS content, the highest values of total GLS content were observed in the hybrid lines harvested in Dłoń (46.22) and Poznań (37.73). It is noteworthy that among the analyzed hybrid lines there were some lines with significantly lower and higher GLS content. The lowest GLS content was noted in Dłoń for MS8 $\mathrm{x}$ $B$. campestris ssp. pekinensis hybrids (6.81) and in Poznań for MS8 x B. campestris ssp. trilocularis hybrid lines (10.94).

The average value of alkene GLS content $(\mu \mathrm{mol} / \mathrm{g}$ seeds) in the control seeds of B. napus - Lira Jet variety was lower than in all analyzed hybrid lines in both location. Also the total GLS value showed a similar dependence.

\section{Fiber content}

The fiber content in the hybrid and parental seeds was expressed as the average value of the neutral detergent fiber (NDF) and the acid detergent fiber (ADF) as a subfraction of the NDF. It was shown that the NDF average content was the lowest for yellow seeded $B$. campestris ssp. trilocularis "Yellow sarson" (22.92\%) compared to other tested parental and hybrid forms (Table 3).

Although there was no significant difference in the NDF average content among the hybrids, the fiber levels were slightly lower in Dłon than in Sołacz. In Dłon, the NDF values ranged in MS8 x B.campestris ssp. trilocularis "Yellow sarson" hybrid lines from $21.93 \%$ to $28.38 \%$. For the other hybrids, some lines with lower fiber content than the parental forms were selected.

\section{Sinapine content}

The sinapine content in seeds of parental forms ranged from $0.76 \%$ in B. carinata to $2.04 \%$ in MS8 line, while in the hybrid lines, it ranged from $0.96 \%$ (MS8 x $B$. carinata, harvested in Poznań) to $2.72 \%$ (MS8 x $B$. campestris ssp. pekinensis), harvested in Dłoń (Table 4).

Generally, in all analyzed hybrid lines, lower values of the average sinapine content compared with the controls was observed.

The value of the variability parameters for the analyzed quality traits in hybrid seeds differed between the crosses. A significant variation was observed for all the parameters except the sinapine content. The widest range was recorded for alkene glucosinolates (4.96$101.08 \mu \mathrm{mol} / \mathrm{g}$ of seeds for MS8 x B. campestris ssp. pekinensis in Dłoń) followed by the ADF for the same hybrid line and location (15.75-24.63\%). The analyses of the variance for glucosinolate content exhibited high values for almost all the tested hybrid lines except one MS8 $\times B$. carinata, which had a very low variance value (28.66 for alkene GLS) and (24.48 for GLS sum) in Poznań. The variance for fiber content in hybrid seeds was lower than for the GLS and ranged from 0.23 (MS8 x B. campestris ssp. pekinensis in Poznań) to 1.54 (MS8 $\mathrm{x} B$. campestris ssp. pekinensis in Dłoń) for the ADF, and from 1.34 (MS8 x B. carinata in Poznań) to 11.35 (MS8 x B. campestris ssp. pekinensis in Dłoń) for the NDF, respectively (Table 3 ). Even lower were the variance values for the sinapine content that ranged from 0.01 in Poznań to 0.08 in Dłoń.

\section{Discussion}

The results of this study show that the analyzed hybrid lines differ in their glucosinolate, fiber and sinapine content. In the experiments, it was observed that four 
Table 3. Fiber content [\%] in the seeds of interspecific hybrids obtained by crossing male sterile line of Brassica napus MS-8 $(\mathrm{AACC}=38)$ with yellow - seeded B. campestris ssp. trilocularis "Yellow Sarson" - (A1A1 = 20), brown - seeded B. campestris ssp. pekinensis $(\mathrm{A} 2 \mathrm{~A} 2=20)$, B. carinata $(\mathrm{BBCC}=34)$ and with $B$. juncea $-(\mathrm{AABB}=18)$ depending on the location $-\mathrm{Dłon}(\mathrm{D})$, Poznań-Sołacz (S)

\begin{tabular}{|c|c|c|c|c|c|c|c|c|c|c|c|}
\hline \multirow{2}{*}{$\begin{array}{c}\text { Hybrids and } \\
\text { parental forms }\end{array}$} & \multirow{2}{*}{ Location } & \multicolumn{5}{|c|}{$\mathrm{ADF}$} & \multicolumn{5}{|c|}{$\mathrm{NDF}$} \\
\hline & & mean & range & $\mathrm{NIR}_{0.05}$ & $\mathrm{SD}$ & Var & mean & range & $\mathrm{NIR}_{0.05}$ & $\mathrm{SD}$ & Var \\
\hline $\mathrm{AC}$ & $\mathrm{S}$ & 18.53 & - & - & - & - & 24.58 & - & - & - & - \\
\hline \multirow{2}{*}{$\begin{array}{l}\mathrm{AC} \times \mathrm{A} 1 \\
(16 \text { lines })\end{array}$} & $\mathrm{S}$ & 19.95 & $18.35-21.89$ & 0.25 & 0.88 & 0.78 & 25.57 & $22.16-29.98$ & 0.58 & 2.04 & 4.16 \\
\hline & $\mathrm{D}$ & 19.31 & $17.24-21.34$ & 0.22 & 1.04 & 1.08 & 24.39 & $21.93-28.38$ & 0.33 & 1.57 & 2.46 \\
\hline $\mathrm{A} 1$ & S & 19.34 & - & - & - & - & 22.92 & - & - & - & - \\
\hline \multirow{2}{*}{$\begin{array}{l}\mathrm{AC} \times \mathrm{A} 2 \\
(56 \text { lines })\end{array}$} & $\mathrm{S}$ & 19.97 & $19.20-21.21$ & 0.14 & 0.47 & 0.23 & 25.01 & $23.01-29.12$ & 0.37 & 1.27 & 1.60 \\
\hline & $\mathrm{D}$ & 19.48 & $15.75-24.63$ & 0.12 & 1.17 & 1.54 & 24.85 & $18.94-29.34$ & 0.22 & 2.11 & 11.35 \\
\hline $\mathrm{A} 2$ & $\mathrm{~S}$ & 19.48 & - & - & - & - & 24.85 & - & - & - & - \\
\hline \multirow{2}{*}{$\begin{array}{l}\mathrm{AC} \times \mathrm{BC} \\
(10 \text { lines })\end{array}$} & $\mathrm{S}$ & 20.10 & $18.35-21.48$ & 0.40 & 0.86 & 0.73 & 25.05 & $22.47-26.35$ & 0.53 & 1.16 & 1.34 \\
\hline & $\mathrm{D}$ & 19.34 & $17.60-21.13$ & 0.28 & 0.96 & 0.92 & 24.60 & $21.34-28.22$ & 0.52 & 1.79 & 3.20 \\
\hline $\mathrm{BC}$ & $\mathrm{S}$ & 21.02 & - & - & - & - & 24.68 & - & - & - & - \\
\hline \multirow{2}{*}{$\begin{array}{l}\mathrm{AC} \times \mathrm{AB} \\
(14 \text { lines })\end{array}$} & $\mathrm{S}$ & 20.33 & $19.13-21.20$ & 0.54 & 0.82 & 0.68 & 25.09 & $23.29-27.68$ & 1.15 & 1.76 & 3.10 \\
\hline & $\mathrm{D}$ & 20.30 & $19.13-21.18$ & 0.17 & 0.56 & 0.31 & 25.92 & $22.82-28.61$ & 0.49 & 1.62 & 2.62 \\
\hline $\mathrm{AB}$ & $\mathrm{S}$ & 20.87 & - & - & - & - & 24.72 & - & - & - & - \\
\hline $\begin{array}{l}\text { Control } \\
\text { - Lira Jet }\end{array}$ & S & 19.12 & - & - & - & - & 25.60 & - & - & - & - \\
\hline
\end{tabular}

Table 4. Sinapine content [\%] in the seeds of interspecific hybrids obtained by crossing male sterile line of Brassica napus MS-8 $(\mathrm{AACC}=38)$ with yellow - seeded B. campestris ssp. trilocularis "Yellow Sarson" - $(\mathrm{A} 1 \mathrm{~A} 1=20)$ brown - seeded B. campestris ssp. pekinensis $(\mathrm{A} 2 \mathrm{~A} 2=20), B$. carinata $(\mathrm{BBCC}=34)$ and with $B$. juncea - $(\mathrm{AABB}=18)$ depending on the location $-\mathrm{D} ł o n$ (D), Poznań-Sołacz (S)

\begin{tabular}{|c|c|c|c|c|c|c|c|c|c|c|}
\hline \multirow{2}{*}{$\begin{array}{l}\text { Hybrids and } \\
\text { parental forms }\end{array}$} & \multicolumn{5}{|c|}{ Dłoń } & \multicolumn{5}{|c|}{ Poznań - Sołacz } \\
\hline & Mean & Range & $\mathrm{NIR}_{0.05}$ & $\mathrm{SD}$ & VAR & Mean & Range & $\mathrm{NIR}_{0.05}$ & $\mathrm{SD}$ & VAR \\
\hline $\mathrm{AC}$ & - & - & - & & & 2.04 & - & - & - & - \\
\hline $\begin{array}{l}\mathrm{AC} \times \mathrm{A} 1 \\
(16 \text { lines })\end{array}$ & 1.40 & $1.13-2.01$ & 0.05 & 0.19 & 0.04 & 1.21 & $1.02-1.51$ & 0.12 & 0.16 & 0.03 \\
\hline $\mathrm{A} 1$ & - & - & - & - & - & 0.88 & - & - & - & - \\
\hline $\begin{array}{l}\text { AC x A2 } \\
(56 \text { lines })\end{array}$ & 1.52 & $1.3-2.72$ & 0.09 & 0.28 & 0.08 & 1.22 & $1.04-1.68$ & 0.05 & 0.14 & 0.01 \\
\hline $\mathrm{A} 2$ & - & - & - & - & - & 0.91 & - & - & - & - \\
\hline $\begin{array}{l}\mathrm{AC} \times \mathrm{BC} \\
(10 \text { lines })\end{array}$ & 1.15 & $1.09-1.19$ & 0.05 & 0.14 & 0.02 & 1.14 & $1.09-1.53$ & 0.05 & 0.12 & 0.01 \\
\hline $\mathrm{BC}$ & - & - & - & - & - & 0.76 & - & - & - & - \\
\hline $\begin{array}{l}\mathrm{AC} \times \mathrm{AB} \\
(14 \text { lines })\end{array}$ & 1.09 & $0.90-1.19$ & 0.16 & 0.14 & 0.02 & 0.96 & $0.60-1.36$ & 0.04 & 0.12 & 0.01 \\
\hline $\mathrm{AB}$ & - & - & - & - & - & 1.09 & - & - & - & \\
\hline Control - Lira Jet & - & - & - & - & - & 1.47 & - & - & - & \\
\hline
\end{tabular}


parental forms (B. campestris ssp. sarson, B. campestris ssp. pekinensis; $B$. carinata and $B$. juncea) demonstrate a much higher average of the alkene glucosinolate content than the hybrid lines. Rapeseed lines and cultivars may be recommended for inclusion in the human diet due to their low specific glucosinolate content. Consequently, we see a possible application of the hybrid lines we identified?/obtained? in the future breeding programs. In oilseed rape, however, the level of genetic diversity in the adopted winter oilseed rape breeding material with double low seed quality (zero erucic, low glucosinolate content) is relatively low due to a lengthy selection procedure of better lines with respect to the seed oil and meal quality. The variation in the amount and pattern of glucosinolates in Brassica plants is attributed to genetic and environmental factors, including plant age, temperature, water stress and soil type (Rosa, 1997). Comparison of the two locations, i.e. the fields in Poznań and Dłoń, revealed a greater variability in the glucosinolate and sinapine content in the tested hybrid lines in Dłoń. This variability may be influenced by better environmental conditions in this region. Since the thinner seed coat meal from the yellow-seeded lines has much lower fiber content than the meal from black-seeded lines, yellow-seeded species of Brassica were also used for hybridization for the experiment. However, as per our results, the fiber content in hybrid lines showed variability in hybrid lines when compared to the parental forms and the control variety, especially in MS8 8 B. campestris ssp. trilocularis and MS8 $\mathrm{x}$ B. campestris ssp. pekinensis hybrid lines.

The elimination of sinapine content will improve the flavor, palatability and nutritional properties of canola seeds and canola meal. Although several methods for removing sinapine have been reported (Fenwick et al., 1979; Dabrowski et al., 1989, Tayaranian and Henkel, 1991, Wojciechowski et al., 1994), none has been proven economical thus far (Wang et al., 1998). Conventional plant breeding or genetic engineering would be a more efficient long term means of lowering or eliminating sinapine levels. Success of a conventional plant breeding program depends on finding genetic variability for sinapine content and developing a suitable analytical methodology to select plants with low sinapine content in the seed. Average sinapine concentrations among the four hybrid lines ranged from 1.09 to $1.52 \%$ in Dłoń, and from 0.96 to $1.22 \%$ in Poznań. Our results were si- milar to those obtained by Taylor et al. (1993) for six cultivars of cabbage, broccoli and cauliflower (0.74-1.20\%). The results obtained in our experiment show that there is a high variability in sinapine content, especially among the haploid lines originating from crosses of $B$. napus with $B$. juncea. This suggests that it might be possible, by selection, to develop rapeseed varieties that are low in sinapine content.

\section{Conclusions}

Generally, all the tested hybrid lines displayed a great increase in the range of variability for the studied quality traits, especially in the glucosinolate and fiber content when compared to the parental forms and the control varieties.

On the basis of the conducted analyses, reduced glucosinolates hybrid lines were selected (7.54-15.76 $\mu \mathrm{mol} / \mathrm{g}$ dry weight of seeds).

The environmental impact on the tested quality traits was observed for both, the glucosinolates and the sinapine content. A higher range of variability for the above-mentioned traits was observed in Dłoń

\section{Acknowledgments}

The authors would like to thank Dr. Budzianowski from the Plant Breeding Strzelce, the IHAR Group, Małyszyn branch in Poland for conducting the chemical analyses of the fiber and glucosinolates content in Brassica seeds. This work is part of the project "Genetic - environmental interactions induced quality traits in lines of Brassica napus L." founded by the Polish Ministry of Agriculture and Rural Development.

\section{References}

Biston R.P., Dardenne P., Cwikowski M., Marlier M., Severin M., Wathelet J.P. (1988) Fast analysis of rapseed glucosinolates by near infrared reflectance spectroscopy. J. Am. Oil Chem. Soc. 65: 1599-1600.

Chen B.Y., Simonsen V., Lannér-Herrera C., Heneen W.K. (1992) A Brassica campestris-alboglabra addition line and its use for gene mapping, intergenomic gene transfer and generation of trisomics. Theor. Appl. Genet. 84: 592-599.

Dabrowski K.J., Rutkowski A., Manimanna S.G., Rowicka A. (1989) The reduction of glucosinolate and sinapine contents under industrial processing of rapeseed. Fat Sci. Technol. 91: 361-363

Fenwick G.R., Hobson-Frohock A., Land D.G., Curtis R.F. (1979) Rapeseed meal and egg taint: Treatment of rape- 
seed meal to reduce tainting potential. Brit. Poultry Sci. 20: 323-329.

Keller W.A., Armstrong K.C. (1977) Embryogenesis and plant regeneration in Brassica napus anther culture. Ca. J. Bot. 55(10): 1383-1388.

Murashige T., Skoog F. (1962) A revised medium for rapid growth and bio-assays with tobaco tissue culture. Physiol. Plant. 15: 473-497.

Nitsh J.P., Nitsh C., Hamon S. (1969) Production de Nicotiana tabacum diploids a partir de cals haploides cultives in vitro. C.R. Acad. Sci. Paris 269: 1275-1278.

Olejniczak J., Adamczak M., Wojciechowski A. (2007) Selection of winter oilseed mutants (Brassica napus L.) with reduced content of antinutritional compounds by the use of near-infrared reflectance spectroscopy (NIRS)). Acta Agrophys. 9(3): 711-717.

Rosa E. (1997) Glucosinolates from flower buds of Portuguese Brassica crops. Phytochemistry 44: 1414-1419.

Tayaranian H., Henkel H. (1991) Processing of rapeseed and meal to reduce the content of sinapine and glucosinolates. in: Proceedings of $8^{\text {th }}$ International Rapeseed Congress, ed. McGregor D.I., Saskatoon, pp. 1555-1560.

Taylor A.G., Churchill D.B., Lee S.S., Bilsland D.M., Cooper T.M. (1993) Color sorting of coated Brassica seeds by fluorescent sinapine leakage to improve germination. J. Amer. Soc. Horticult. Sci. 118: 551-556.

Thies W. (1982) Complex-formation between glucosinolates and tetrachloropalladate (II) and its utilization in plant breeding. Fette Seifen Anstrichmittel. 84: 342-388.
Wang S.X., Oomah B.D., Ian McGregor D., Downey R.K. (1998) Genetic and seasonal variation in the sinapine content of seed from Brassica and Sinapis species. Can. J. Plant Sci. 78: 395-400.

Wojciechowski A. (1985) Interspecific hybrids between Brassica campestris and B. oleracea. I. Effectiveness of crossing. Observations of pollen tube growth. The course of embriogenesis. Genet. Polon. 26(4): 423-436.

Wojciechowski A., Kott L., Beversdorf W. (1994) Content of sinapine in haploid embryos of rapeseed (Brassica napus) from microspore in in vitro culture. Rośliny Oleiste -Oilseed Crops 15: 105-110.

Wojciechowski A. (1998) Regeneration abilities of chosen genotypes of Brassica in in vitro cultures. Ann. Agricult. Univ. Poznan 289: 1-58.

Velasco L., Möllers C. (1998) Nondestructive assessment of sinapine acid esters in Brassica species: n. Evaluation germplasm and identification fenotype with reduce level. Crop Sci. 38: 1650-1654.

Velasco L., Fernandez-Martinez J.M., De Haro A. (1999) Intraspecific breeding for reduced glucosinolate content in Ethiopian mustuard (Brassica carinata A. Braun). Euphytica 106: 125-130.

White P.R. (1963) The cultivation of animal and plant cells. The Ronald Press, New York.

zum Felde T. (2005) Genetische variation und vererbung von sinapinsaure-verbindungen im raps (Brassica napus L.). Manuscript I, 1-29, Universitaet in Gottingen. 